\title{
LyTONEPAL: long term outcome of neonatal hypoxic encephalopathy in the era of neuroprotective treatment with hypothermia: a French population-based cohort
}

Thierry Debillon ${ }^{1,2^{*}}$ (D) Nathalie Bednarek ${ }^{3,4}$, Anne Ego ${ }^{2,5}$ and the LyTONEPAL Writing Group

\begin{abstract}
Background: Hypoxic-ischemic encephalopathy (HIE) is a rare neonatal condition affecting about 1\%o births. Despite a significant improvement in the management of this condition in the last ten years, HIE remains associated with high rates of death and severe neurological disability. From September 2015 to March 2017, a French national cohort of HIE cases was conducted to estimate the extent of long-term moderate and severe neurodevelopmental disability at 3 years and its determinants.
\end{abstract}

Methods: This prospective population-based cohort includes all moderate or severe cases of HIE, occurring in newborns delivered between 34 and 42 completed weeks of gestation and admitted to a neonatal intensive care unit. Detailed data on the pregnancy, delivery, and newborn until hospital discharge was collected from the medical records in maternity and neonatology units. All clinical examinations including biomarkers, EEG, and imaging were recorded. To ensure the completeness of HIE registration, a registry of non-included eligible neonates was organized, and the exhaustiveness of the cohort is currently checked using the national hospital discharge database. Follow-up is organized by the regional perinatal network, and 3 medical visits are planned at 18, 24 and 36 months. One additional project focused on early predictors, in particular early biomarkers, involves a quarter of the cohort.

Discussion: This cohort study aims to improve and update our knowledge about the incidence, the prognosis and the etiology of HIE, and to assess medical care. Its final objective is to improve the definition of this condition and develop prevention and management strategies for high-risk infants.

Trial registration: NCT02676063. Date of registration (Retrospectively Registered): February 8, 2016.

Keywords: Late preterm and term births, Cohort, Population-based study, Hypoxic ischemic encephalopathy, Therapeutic hypothermia

\footnotetext{
* Correspondence: TDebillon@chu-grenoble.fr

${ }^{1}$ Neonatology Department, University Hospital Grenoble Alpes, Grenoble,

France

${ }^{2}$ TIMC-IMAG, Grenoble Institute of Engineering, CNRS, Grenoble Alpes

University, Grenoble, France
}

(c) The Author(s). 2018 Open Access This article is distributed under the terms of the Creative Commons Attribution 4.0 International License (http://creativecommons.org/licenses/by/4.0/), which permits unrestricted use, distribution, and reproduction in any medium, provided you give appropriate credit to the original author(s) and the source, provide a link to the Creative Commons license, and indicate if changes were made. The Creative Commons Public Domain Dedication waiver (http://creativecommons.org/publicdomain/zero/1.0/) applies to the data made available in this article, unless otherwise stated. 


\section{Background}

Hypoxic ischemic encephalopathy: Definition, incidence and risk factors

Hypoxic-Ischemic Encephalopathy is defined as the clinical manifestation of impaired neonatal brain function following asphyxia due to an antenatal and/or perinatal adverse event. Various criteria (biological, clinical and sometimes electrophysiological) are used to define the severity of the neurological damage [1], many of them being included in Sarnats' original classification [2].

The incidence of HIE is currently imprecise with numbers ranging from 1 to 8 per 1000 live births worldwide [3, 4], but is nearer to between 1 and 2 per 1000 full term births in population-based studies conducted in high income countries [5-7]. In a regional population-based study in France, the prevalence of moderate or severe HIE per 1000 live births was estimated to be 0.86 (95\% CI 0.61 to 1.10 ) in 2000 [8].

The identification of pregnancies at risk of intrapartum fetal asphyxia is a longstanding issue [9-13] and antepartum and intrapartum factors have been identified [5, 14]. Maternal pyrexia, a persistent occipito-posterior position, an acute intrapartum event (hemorrhage, maternal convulsions, uterine rupture, snapped cord, and birth before arrival at an obstetric facility), and instrumental vaginal delivery or emergency caesarean section are all labor-related events associated with HIE.

\section{Management of HIE and short and long-term outcomes}

A meta-estimate of the proportion of death, cerebral palsy or motor/cognitive impairment (more than 2 standard deviations below the norm) was $47 \%$ (95\% CI 36 to 57 ) at 3 years and older [15]. Among other outcomes identified during early childhood, 10-12\% will develop post-neonatal epilepsy [16-21], 9\% hearing loss or deafness, and $26 \%$ impaired vision or blindness [21].

Therapeutic hypothermia $(\mathrm{TH})$ has been shown to safely improve the developmental outcome of infants with HIE [22-24], and reduces mortality or major neurodevelopmental disability at 18 months of age with a risk ratio (RR) of 0.75 (95\% CI 0.68 to 0.83 ) [25]. Shankaran et al. reported a rate of death or survival with an IQ below 70 at 6 to 7 years of 47 and $62 \%$ in the hypothermia versus control groups, respectively [26].

French guidelines on TH for HIE infants were published by the French Society of Neonatology in 2010 [27], but a multicenter study has shown that the implementation of these guidelines has been heterogeneous [28].

Predicting mortality and neurodevelopmental outcomes The early prediction of morbidity and mortality is of crucial importance to initiate adequate neuroprotective care, early rehabilitation programs or eventually to discuss palliative care following the first week of life. Different tools derived from Sarnats' clinical score [2] or Amiel-Tison's score [29] have been proposed to predict short term morbidity and mortality. The Thompson score, which tests 9 independent clinical items is now increasingly used, considering its relevant predictive values at 12 and 24 months [30, 31].

Classification based on conventional electroencephalography (cEEG) signs, which play a significant role in making a prognosis, have been developed for full-term infants $[32,33]$. A simplified version of the cEEG technique, amplitude-integrated EEG (aEEG) is widely used in northern Europe in neonatology, and allows cerebral monitoring from birth to several days of life. It appears as the most promising test in a recent meta-analysis of the prognostic values of current tests for neurodevelopmental outcomes (12-18 months) following perinatal asphyxia [34], with relevant performance as early as the first $6 \mathrm{~h}$ of life $[35,36]$.

While conventional Magnetic Resonance Imaging (MRI) is useful, it often only reveals subtle changes in response to injury during the first 5 days following perinatal asphyxia [37-39]. In contrast, diffusion weighted MRI gives more conspicuous findings which are seen earlier $[40,41]$. In the meta-analysis of van Laerhoven (1306 full-term neonates), diffusion weighted MRI in the first week performed best in terms of specificity $(0.89,95 \% \mathrm{CI}$ 0.62-0.98), while T1/T2 - weighted MRI (in the first 2 weeks) was highly relevant with excellent sensitivity (0.98, 95\% CI 0.80-1.00) [34].

Finally, several potential biomarkers have been evaluated in the context of HIE: IL-6, an inflammatory cytokine produced by T-cells and macrophages [42, 43], cardiac troponin I (cTnI) a marker of ischemic myocardial muscle insult $[44,45]$, acylcarnitins, markers of mitochondrial dysfunction [46], and ischemia-modified albumin [47]. In addition, a French team has proposed matrix metalloproteinases (MMP) and their inhibitors (TIMP) as potential markers of the extent of HIE damage in newborns and consequently the prognosis [48].

Outstanding issues about HIE relate mainly to the long term moderate and severe neurodevelopmental outcomes, the early identification of children at risk, and the analysis of recent changes in medical practice. To our knowledge there is no recent or ongoing population-based study in developed countries addressing these questions [24, 49, 50]. The Long term prognosis of neonatal hypoxic encephalopathy in the era of neuroprotective treatment with hypothermia (LyTONEPAL) project is a national prospective cohort study funded by the French Ministry of Health. It received ethics committee in approval 2014 and was launched in 2015. 


\section{Objectives}

The main objective is the occurrence of death, or severe or moderate neurodevelopmental disability at 3 years of age, in a large population-based cohort of children born at full-term, or late preterm, with moderate or severe HIE. The study aims also to 1 ) identify the very early prognostic factors, including specific new biomarkers, of poor outcome at 3 years of age; 2) analyze the predictive value of the clinical examinations during the first weeks of life; 3 ) describe and evaluate the different neuroprotective treatment strategies, including $\mathrm{TH}$.

The study of potential new biomarkers is the object of an ancillary study requiring early, non-routine, laboratory analyses: interleukin-6, metalloproteinase-9, TIMP-1, ischemia-modified albumin (a marker of hypoxia), troponin I, acylcarnitins and amino acids; assayed in the first $6 \mathrm{~h}$ of life and again at $72 \mathrm{~h}$.

\section{Methods}

\section{Study design}

All French metropolitan regions and overseas administrative areas were invited to participate in the study, and a neonatologist from one level III neonatal intensive care unit (NICU) per region was appointed as the regional coordinating investigator. These physicians are almost always the heads of the neonatology departments of the regional university hospital. Senior professionals familiar with the long-term support of families of children with HIE in their respective centers are in charge of each center. A clinical research assistant is assigned to each region to collect data, check the exhaustive registration of HIE cases, and plan patient follow up.

Sixty-eight level III intensive care units in 22 French regions (22 of the 23 metropolitan regions and 2 overseas administrative areas) are participating in the study. One region representing 27,300 births (3.4\%) of the 800,000 births registered each year in France refused to participate. Babies were included from September 2015 to March 2017. Nineteen centres participate to the ancillary study, and a quarter of the total cohort is involved in this project. Consecutive inborn and outborn neonates transferred to the NICU, were screened by the neonatologists who provided information to parents, registered informed consent and included the neonate in the cohort. As permitted by French regulations on clinical research, a datasheet of minimal information was completed in cases of refusal to participate or circumstances in which information delivery was difficult for ethical reasons (early neonatal deaths) or when the parents did not speak French. Participating centers were invited to adhere to current guidelines and perform all clinical examinations necessary for the optimal management of HIE. At discharge from the neonatology unit, the parents were informed of and asked to consent to a follow-up plan, to the age of 3 years, drawn-up on a regional basis.

\section{Participants}

Eligible neonates were babies born at 34 weeks gestational age or more, presenting: 1) early neurological distress with clinical signs of moderate to severe HIE on standardized neurological examination performed by a senior investigator, 2) biological criteria of asphyxia during the first hour of life, including 2a) severe biological signs of asphyxia or $2 b$ ) moderate or no biological signs of asphyxia with perinatal adverse events (Table 1). Neonates with congenital malformations, chromosomal disorders and congenital neuromuscular disorders were not-included or subsequently excluded, as the pathogenesis of HIE requires several days to be confirmed.

\section{Baseline data collection and follow-up organization}

Neonatal data collection was done by neonatologists and clinical research assistants from the medical records of

Table 1 HIE neurological and biological inclusion criteria for the LyTONEPAL cohort

Neurological signs

Biological criteria indicating asphyxia during the first hour after birth in a sample of umbilical-cord blood or any other blood sampled
- Moderate HIE: lethargy, hyper-reflexia, myosis, bradycardia, seizures, hypotonia with weak suck and poor Moro reflex

- Severe HIE: stupor, flaccidity, small to mid-position pupils that react poorly to light, decreased stretch reflexes, hypothermia or absent Moro reflex

- Severe biological signs: $\mathrm{pH} \leq 7.0$ or less or a base deficit $\geq 16 \mathrm{mmol}$ per liter - Moderate/absent biological signs with additional perinatal events:

$\circ 7.0<\mathrm{pH} \leq 7.15$, or $10 \leq \mathrm{a}$ base deficit $<16 \mathrm{mmol}$ per liter, or blood gas measurement unavailable

o With:

- an acute perinatal event (e.g. late or variable decelerations, cord prolapse, cord rupture, uterine rupture, maternal trauma, hemorrhage, or cardiorespiratory arrest)

- or an abrupt change in fetal heart rate (FHR), defined as a persistent abnormal FHR after a period of normal tracing: bradycardia or prolonged deceleration, persistent variable decelerations, persistent late decelerations, and reduced heart variability

- or either a 10-min Apgar score of 5 or less or assisted ventilation initiated at birth and continued for at least $10 \mathrm{~min}$. 
the mother and the neonate. Data included characteristics of the mother, her pregnancy and the circumstances of delivery, the neonate's birth admission to the NICU, hospital stay in neonatal units, hospital discharge, and the organization of care (Table 2).

The follow-up plan was presented to families before hospital discharge. Follow-up includes three medical visits at 18, 24 and 36 months. At 6 month the mother is asked to fill in a questionnaire concerning post traumatic maternal stress [43]. At each visit information is collected on post-neonatal care (hospital admissions, medical visits, etc.), growth according to standardized anthropometric measurements, motor development, neurologic complications including seizures and all medical treatments. Motor disorders, especially cerebral palsy, are detected using the diagnostic criteria of the Surveillance of Cerebral Palsy in Europe (SCPE) network [44], based on the Gross Motor Function Classification System (GMFCS) [45]. The 18-month visit includes screening for autism [46] and a parental questionnaire concerning the home environment of the child and the family's socio-economic status. Neurodevelopmental outcomes are assessed at 24 months using the revised Brunet Lezine test [47], the Age and Stages Questionnaire
(ASQ) score [48], and a questionnaire screening for language disorders ("Inventaires Français du Développement Communicatif" adapted from the MacArthur communicative development inventories by Fenson et al.) [49]. The ASQ score is measured again at 36 months, and any sensorial impairment sought by an audiogram and an ophthalmological examination.

\section{Data management and completeness of HIE registration}

Data are registered in an electronic case report form, with a secure interface. Parents are contacted by email at 6 months and requested to log-in to the same database to complete self-administered questionnaires. Data entry and quality control of responses and missing data are performed continuously.

Using the national hospital discharge database, we have defined an algorithm to seek unreported cases of HIE likely to have been eligible for inclusion in the cohort. This algorithm combines gestational age ( $\geq 34$ weeks), date of hospital discharge, the diagnosis code for HIE, P91.6 in the International Classification of Disease 10th edition (recorded as the main or a related diagnosis), and hospital stay in a level III neonatology units of the participating regions. It excludes infants with chromosomal

Table 2 Maternal and neonatal data collection until neonatal hospital discharge

\begin{tabular}{|c|c|}
\hline Mother and pregnancy characteristics & $\begin{array}{l}\text { - Maternal age, parity, educational level, occupation, history of previous pregnancies, } \\
\text { medical history and complications of the current pregnancy }\end{array}$ \\
\hline Circumstances of birth & $\begin{array}{l}\text { - Labor and delivery mode: } \\
\text { onset of labor, mode of delivery, intrapartum complications, fetal heart rate monitoring } \\
\text { - Neonatal characteristics: } \\
\text { gestational age, birthweight, gender, small for gestational age (<10th percentile), 1, } 5 \\
\text { and } 10 \text { min Apgar scores, cord or arterial pH, base deficit within the first hour of life, } \\
\text { neonatal transfer } \\
\text { - Care in delivery room: } \\
\text { O2, ventilation, resuscitation } \\
\text { - Placental examination and fetal autopsy (if performed) }\end{array}$ \\
\hline Admission in NICU & $\begin{array}{l}\text { - Standardized neurological examination: } \\
\text { Sarnat classification and Thompson score during the first week of life. } \\
\text { - First clinical investigations: } \\
\text { Electrophysiological examination (cEEG or aEEG) and neuro-imaging }\end{array}$ \\
\hline Hospital stay in neonatal units & $\begin{array}{l}\text { - Clinical investigations } \\
\text { Electrophysiological examination (standard or amplitude-integrated), Cerebral ultrasound } \\
\text { exams (Doppler and morphological), Brain MRI (diffusion -weighted and standard), } \\
\text { Standard blood tests (heart, liver, kidney). } \\
\text { - Treatment: } \\
\text { analgesia, sedatives, anticonvulsant treatment, cooling or other neuroprotective strategies, } \\
\text { ventilation, nutrition } \\
\text { - Neonatal morbidity and mortality: } \\
\text { pulmonary, cardiac, renal or liver pathologies, multi-organ system failure, neonatal death } \\
\text { (date and presumed cause) }\end{array}$ \\
\hline Hospital discharge from neonatal unit & $\begin{array}{l}\text { - Standardized neurological examination: } \\
\text { Sarnat definition, Thompson score, and Amiel-Tison neurological assessment. } \\
\text { - Hospital discharge: } \\
\text { discharge home, discharge to another care facility, death } \\
\text { - Presumed circumstances or cause of HIE according to the neonatologist: } \\
\text { Identified maternal, obstetrical, or neonatal conditions and events }\end{array}$ \\
\hline Organization of care & $\begin{array}{l}\text { - Place of birth, level of care of the maternity ward, timing of transfer and admission to } \\
\text { NICU, transport conditions, level of care of the first and subsequent neonatal units, } \\
\text { length of hospital stay }\end{array}$ \\
\hline
\end{tabular}


abnormalities (diagnosis code Q9*). This discharge database is crossed with the cohort database. For each newly suspected case admitted to a NICU, the investigating neonatologist is asked to consult the medical notes and check the inclusion criteria. If HIE is confirmed, these neonates are registered in the inventory of non-included eligible neonates with the collection of minimal data. These investigations are still in progress.

\section{Study outcomes}

The primary outcome measure is a combined criterion, including death or moderate or severe neurodevelopmental deficiency at 3 years of age.

Severe neurodevelopmental deficiency is defined as:

- intellectual impairment (mental score $>2$ sd below the mean or intellectual quotient (IQ) $<70$ according to the revised Brunet Lezine Score and ASQ scores),

- or cerebral palsy (GMFCS of 3-5),

- or sensorial impairment (bilateral blindness with vision $<20 / 200$ acuity or deafness requiring amplification $>60 \mathrm{~dB}$ ),

- or persistent disorder defined as recurrent seizures after discharge from the NICU requiring anticonvulsive therapy.

Moderate disability was defined as:

- intellectual impairment ( $1 \mathrm{sd}<$ mental score $\leq 2 \mathrm{sd}$ below the mean or $70 \leq \mathrm{IQ}<85)$,

- cerebral palsy (GMFCS of 1-2),

- or hearing impairment requiring no amplification.

Secondary outcomes are the estimation of the relevance of very early prognostic factors, including the specific new biomarkers, clinical, biological, EEG and neuroimaging examinations during the first weeks of life, and the analysis of the effect of neuroprotective strategies, including therapeutic hypothermia.

\section{Sample size calculation}

The sample size was calculated so as to demonstrate differences in prognosis according to risk factors. We expected a proportion of poor outcomes at 3 years of $70 \%$ versus $85 \%$ among unexposed versus exposed babies (difference rate of $15 \%$, RR of 1.2 ). With $15 \%$ of newborns exposed to risk factors, the total sample size needed was 552 children followed-up at 3 years (with an alpha error of 0.05 and power of 0.80 ). We considered that the incidence of moderate or severe HIE might be around $1 \%$ births, corresponding to 800 cases of moderate or severe HIE per year in France, with a death rate of $20 \%$ before hospital discharge, a participation rate of
$80 \%$ among survivors, and $10 \%$ patients lost to follow-up at 3 years. Consequently, the sample size of 552 estimated above was increased by a factor of 1.28 , leading to a sample of 706 neonates with HIE. A 12 to 18 month period of recruitment was planned in order to reach this sample size.

\section{Statistical analysis}

Children lost to follow-up will be compared to those enrolled with complete follow up for baseline characteristics. Subsequent analyses will be performed for each phase of the study, baseline data collection and follow-up.

Descriptive data summaries will be generated using means and standard deviations (or medians and inter-quartile range) for quantitative variables, and frequency distributions (total number, frequency and 95\% CI) for qualitative variables.

Bivariate analyses will be performed to study the association between risk factors and short-term and long-term outcomes using analysis of variance (or a Kruskall-Wallis test) for continuous variables or Chi-square (or Fisher exact tests) for qualitative variables.

Adjusted relative risks and their 95\% CI for the different outcomes will be determined using multilevel logistic regression analysis. A hierarchical logistic regression model will enable us to distinguish the individual (maternal and neonatal) variables from other variables associated with the organization of care such as the level of care in the maternity wards or the characteristics of the NICU, and to estimate the amount of variability within these levels.

The predictive ability of neonatal characteristics will be explored by estimating sensitivity, specificity, predictive values and likelihood ratios with their confidence intervals. The predictive accuracy concerning adverse outcomes will be defined as the proportion of correctly classified cases (sum of true positives and true negatives). The biological cut-off for quantitative biomarkers will be determined using Receiver Operating Characteristic (ROC) curves. Areas under the curve (AUC) of $90-100 \%$ will be considered as excellent and those between 80 and $90 \%$ considered as good. Analysis of simultaneous predictors of outcomes will be conducted using a stepwise process involving multivariable logistic regression and ROC curve analysis performed on the outcome probabilities obtained via logistic regression modeling.

$P$-values less than 0.05 will be considered statistically significant and statistical analysis will be conducted using Intercooled STATA (Version 13, Stata Corporation, College Station, TX, USA).

\section{Ethics approval and consent to participate}

Because this study concerns newborn child, the information and the consent was obtained from both parents. For each eligible neonate, an information form was delivered 
to parents. A first oral consent to participate were requested by the neonatologist at the inclusion concerning the baseline data collection during hospitalization. If this consent was not obtained, the parents signed the information form to refuse their participation. In this case and according to French regulations, these neonates were registered in the inventory of non-included eligible neonates with the collection of anonymous minimal data.

At the end of the neonatal hospitalization a second but written consent was requested to participate to the standardized follow-up, and was signed by both parents and the neonatologist. Babies of parents who refused to participate were followed-up according to the usual practices of the center. According to French regulations, parents have a permanent right of access and rectification to their personal data, and can also leave the cohort at any time.

According the French law, the study protocol, including ethics and consent to participate, was approved by the Advisory National Committee on the treatment of personal health data for research purposes (Comité Consultatif sur le Traitement de l'Information en matière de Recherche sur la Santé, approval granted November 20, 2014; reference number 14.724. The authorizations were obtained:

- from the National French data protection authority (Commission Nationale Informatique et Libertés) on March 27, 2015; DR-2015-136

- and from the Regional Ethics committee CPP SouthEast V (Comité de Protection des Personnes Sud Est; Institutional Review Board n5891) on July 18, 2014.

\section{Project governance}

A national scientific and steering committee including pediatricians, obstetricians, perinatal epidemiologists and a project manager was constituted to organize the implementation and the general supervision of the cohort. At the regional level, a level III NICU hospital and a coordinating committee were appointed to handle the funding allotted to the region, and monitor recruitment and follow-up.

\section{Discussion}

Late preterm and term newborns with HIE will face a range of medical, psychological, and social problems that raise specific questions at birth and thereafter. The need for information on the prevalence, causes, and consequences of HIE requires large population-based cohort studies with a long-term follow-up. Particularly because several changes in the management of HIE have occurred during the past decade and the risk factors for impaired neurodevelopment must be revisited.
Our cohort study offers an original approach because it will allow us to describe the initial clinical contexts linked to poor outcomes, including moderate disability. Moreover, in addition to full-term neonates, late preterm are included, a subgroup for which little data exists about HIE. The establishment and follow-up of this cohort and the collection of detailed data will increase our understanding about: 1) clinical, biological, electrophysiological and brain imaging predictors of long-term outcomes; 2) current care and management of HIE children in the light of recent progress in medical practices, and the particular role of the generalization of hypothermia treatment; 3 ) the organization of care and decision making in critical clinical situations.

Our findings should provide strong criteria to select the best candidates for neuroprotective strategies at the earliest possible stage. The increased knowledge we will gain about HIE prognosis may contribute to improving the relevance of information given to parents during the stay in the NICU, which is a crucial issue for neonatologists. Its importance is highlighted in the French regulations concerning pediatric intensive care. Moreover, it could provide a highly relevant contribution to ethical discussions and the current position regarding end of life decisions may need be updated in the light of the findings of our project.

\section{Abbreviations}

aEEG: Amplitude-integrated electroencephalography; ASQ: Age and stages questionnaire; AUC: Area under the curve; CEEG: Conventional

electroencephalography; CPP: Comité de protection des personnes; cTnl: Cardiac troponin I; GMFCS: Gross motor function classification system; HIE: Hypoxic-ischemic encephalopathy; IQ: Intellectual quotient; MMP: Matrix metalloproteinases; MRI: Magnetic resonance imaging; NICU: Neonatal intensive care unit; RR: Risk ratio; SCPE: Surveillance of cerebral palsy in Europe; TH: Therapeutic hypothermia; TIMP: Inhibitors of matrix metalloproteinases

\section{Acknowledgements}

We are grateful for the participation of all families of newborns in the LyTONEPAL cohort study and for the cooperation of all maternity and neonatal units in France. We thank members of the LyTONEPAL Study Group and all the regional teams participating in the study for their substantial contribution to the conception, design, and acquisition of data.

- LyTONEPAL Writing Group: Pierre-Yves Ancel, Olivier Baud, Nathalie Bednareck, Marie-Laure Charkaluk, Clothilde Desrobert, Thierry Debillon, Catherine de Launay du Couedic, Anne Ego, Cyril Flamant, Pierre Gressens, Gilles Kayem, Stephane Marret, Juliana Patkail, Loic Senthiles, Elie Saliba

- LyTONEPAL Study Group: Alsace: D Astruc, (Strasbourg), J Nakhleh (Mulhouse); Aquitaine: O Brissaud (Bordeaux), P Jouvencel (Bayonne), T Mansir, K Norbert (Pau); Auvergne: G Gremerand (Clermont-Ferrand); Basse-Normandie: A Cénéric (Caen); Bourgogne: C Chantegret, Dr. Kaletas (Dijon); Bretagne: J-M Roué (Brest), M Gromand (Rennes), E Boutaric, J Chauvel, A Busnel (St-Brieuc), A Sevestre (Vannes); Centre: E Saliba, A Bouissou, E Lopez, G Favrais (Tours), J Guerreiro, E Werner (Orléans); Champagne-Ardenne: N Bednarek, P Venot (Reims), I Arnault, B Kassis-Makhoul (Troyes); Franche-Comté: G Thiriez, T Dabudyk (Besançon); Haute-Normandie: A Chadie, T Blanc (Rouen), J Mourdie (Le Havre); llede-France: C Huon (Colombes), F Decobert, C Jung G Dassieu, C Danan, X Durrmeyer (Créteil), M Granier (Evry), O Baud, S Soudee, V BIRAN (Robert Debré), I Guellec (Trousseau), N Yousef (Bicêtre), G Ciarlo, A DURANDY 
(Poissy), J Patkai (Port-Royal), A Lapillonne, C Elie (Necker), V Zupan, R Ben Ammar, Y Soreze (Clamart), P Daoud, B Heller Roussin (Montreuil), D Mellah, L Karaoui (Meaux), D Brault (Argenteuil), P Boize, S Merbouche, M Saad, P Boize, C Miler (Pontoise), F Goudjil (St Denis); LanguedocRoussillon: G Cambonie, M Badr (Montpellier), R Salloum (Perpignan), M Di Maio (Nîmes); Limousin: F Mons (Limoges); Midi-Pyrénées: MO Marcoux (Toulouse); Poitou-Charentes: K Husseini, A Parizel, E Ruiz NordPas-de-Calais: F Flamein, S Joriot (Lille), S Klosowski (Lens), F Lapeyre C Dewitte (Valenciennes), J Ghesquiere, I Guilhoto, L Dusol (Arras), L Egreteau (Calais), Z Osman, M Raqbi (Creil); PACA et Corse: C Desrobert, V Brevaut (Marseille), J Oertel, C Dageville, S Desmet, F Casagrande (Nice); Pays de Loire: C Flamant (Nantes), G Gascoin S le Bouedec (Angers), Y Montcho (Le Mans); Picardie: G Ghostine (Amiens); Rhône-Alpes: N Bouchon (Chambéry), O Claris, JC Picaud, P Vo Van, CM Loys (Lyon), A Ego, T Debillon (Grenoble), H Patural (Saint-Etienne); Martinique: SK Martinon (Fort de France); La Réunion: JB Gouyon (Saint-Pierre), S Samperiz, D Ramful (Saint-Denis).

\section{Funding}

This project was funded by the 2013 French program for Hospital Clinical Research (PHRC-N-13-0327), which is a grant supported by the French Ministry of Social Affairs and Health, and selection includes international external peer review of scientific quality.

\section{Availability of data and materials}

The datasets used and/or analyzed during the current study are available from the corresponding author on reasonable request.

\section{Authors' contributions}

The protocol was developed by $T D, A E, N B$, and approved by the scientific leaders in each region. All members of the LyTONEPAL Writing Group contributed to the design of the study, the development of the questionnaires in a series of workshops, and acquisition of the data. TD and AE drafted the manuscript. The final version has been approved by the entire LyTONEPAL Writing group.

\section{Ethics approval and consent to participate}

For each eligible neonate, an information form was delivered to parents. A first oral consent to participate were requested by the neonatologist at the inclusion concerning the baseline data collection during hospitalization. If this consent was not obtained, the parents signed the information form to refuse their participation. In this case and according to French regulations, these neonates were registered in the inventory of non-included eligible neonates with the collection of anonymous minimal data.

At the end of the neonatal hospitalization a second but written consent was requested to participate to the standardized follow-up, and was signed by both parents and the neonatologist. Babies of parents who refused to participate were followed-up according to the usual practices of the center According to French regulations, parents have a permanent right of access and rectification to their personal data, and can also leave the cohort at any time.

According the French law, the study protocol, including ethics and consent to participate, was approved by the Advisory National Committee on the treatment of personal health data for research purposes (Comité Consultatif sur le Traitement de l'Information en matière de Recherche sur la Santé, approval granted November 20, 2014; reference number 14.724. The authorizations were obtained:

- from the National French data protection authority (Commission Nationale Informatique et Libertés) on March 27, 2015; DR-2015-136

- and from the Regional Ethics committee CPP South-East V (Comité de Protection des Personnes Sud Est; Institutional Review Board n5891) on July 18, 2014

\section{Consent for publication}

Not applicable (anonymous and collective data only).

\section{Competing interests}

The authors declare that they have no competing interests.

\section{Publisher's Note}

Springer Nature remains neutral with regard to jurisdictional claims in published maps and institutional affiliations.

\section{Author details}

${ }^{1}$ Neonatology Department, University Hospital Grenoble Alpes, Grenoble, France. ${ }^{2}$ TIMC-IMAG, Grenoble Institute of Engineering, CNRS, Grenoble Alpes University, Grenoble, France. ${ }^{3}$ Neonatology Department, University Hospital Alix de Champagne, Reims, France. ${ }^{4}$ CReSTIC, Champagne-Ardennes University, EA3804 Reims, France. ${ }^{5}$ Public Health Department, University Hospital Grenoble Alpes, Grenoble, France.

Received: 11 June 2018 Accepted: 19 July 2018

Published online: 01 August 2018

\section{References}

1. Kurinczuk JJ, Barralet JH, Redshaw M, Brocklehurst P. Monitoring the incidence of neonatal encephalopathy-what next? Report to the patient safety research Programme. Oxford: National Perinatal Epidemiology Unit; 2005.

2. Sarnat HB, Sarnat MS. Neonatal encephalopathy following fetal distress. A clinical and electroencephalographic study. Arch Neurol. 1976;33(10):696-705.

3. Kurinczuk JJ, White-Koning M, Badawi N. Epidemiology of neonatal encephalopathy and hypoxic-ischaemic encephalopathy. Early Hum Dev. 2010:86(6):329-38

4. Yates HL, McCullough S, Harrison C, Gill AB. Hypoxic ischaemic encephalopathy: accuracy of the reported incidence. Arch Dis Child Fetal Neonatal Ed. 2012;97(1):F77-8.

5. Badawi N, Kurinczuk JJ, Keogh JM, Alessandri LM, O'Sullivan F, Burton PR, Pemberton PJ, Stanley FJ. Intrapartum risk factors for newborn encephalopathy: the western Australian case-control study. BMJ. 1998:317(7172):1554-8

6. Smith J, Wells L, Dodd K. The continuing fall in incidence of hypoxic-ischaemic encephalopathy in term infants. BJOG. 2000;107(4):461-6.

7. Thornberg E, Thiringer K, Odeback A, Milsom I. Birth asphyxia: incidence, clinical course and outcome in a Swedish population. Acta Paediatr. 1995;84(8):927-32.

8. Pierrat V, Haouari N, Liska A, Thomas D, Subtil D, Truffert P, Groupe d'Etudes en Epidemiologie P. Prevalence, causes, and outcome at 2 years of age of newborn encephalopathy: population based study. Arch Dis Child Fetal Neonatal Ed. 2005;90(3):F257-61.

9. Aylward GP. Perinatal asphyxia: effects of biologic and environmental risks. Clin Perinatol. 1993;20(2):433-49.

10. Levene ML, Kornberg J, Williams TH. The incidence and severity of postasphyxial encephalopathy in full-term infants. Early Hum Dev. 1985;11(1):21-6.

11. MacDonald HM, Mulligan JC, Allen AC, Taylor PM. Neonatal asphyxia. I. Relationship of obstetric and neonatal complications to neonatal mortality in 38,405 consecutive deliveries. J Pediatr. 1980;96(5):898-902.

12. Low JA, Simpson LL, Tonni G, Chamberlain S. Limitations in the clinical prediction of intrapartum fetal asphyxia. Am J Obstet Gynecol. 1995;172(3):801-4.

13. Milsom I, Ladfors L, Thiringer K, Niklasson A, Odeback A, Thornberg E. Influence of maternal, obstetric and fetal risk factors on the prevalence of birth asphyxia at term in a Swedish urban population. Acta Obstet Gynecol Scand. 2002;81(10):909-17.

14. Badawi N, Kurinczuk JJ, Keogh JM, Alessandri LM, O'Sullivan F, Burton PR, Pemberton PJ, Stanley FJ. Antepartum risk factors for newborn encephalopathy: the western Australian case-control study. BMJ. 1998:317(7172):1549-53.

15. Pin TW, Eldridge B, Galea MP. A review of developmental outcomes of term infants with post-asphyxia neonatal encephalopathy. Eur J Paediatr Neurol. 2009;13(3):224-34.

16. Robertson C, Finer N. Term infants with hypoxic-ischemic encephalopathy: outcome at 3.5 years. Dev Med Child Neurol. 1985;27(4):473-84.

17. Robertson CM, Finer NN. Educational readiness of survivors of neonatal encephalopathy associated with birth asphyxia at term. J Dev Behav Pediatr. 1988;9(5):298-306

18. Robertson CM, Finer NN, Grace MG. School performance of survivors of neonatal encephalopathy associated with birth asphyxia at term. J Pediatr. 1989:114(5):753-60.

19. Toet MC, Groenendaal F, Osredkar D, van Huffelen AC, de Vries LS. Postneonatal epilepsy following amplitude-integrated EEG-detected neonatal seizures. Pediatr Neurol. 2005;32(4):241-7. 
20. Pisani F, Orsini M, Braibanti S, Copioli C, Sisti L, Turco EC. Development of epilepsy in newborns with moderate hypoxic-ischemic encephalopathy and neonatal seizures. Brain Dev. 2009;31(1):64-8.

21. Mwaniki MK, Atieno M, Lawn JE, Newton CR. Long-term neurodevelopmental outcomes after intrauterine and neonatal insults: a systematic review. Lancet. 2012;379(9814):445-52.

22. Azzopardi D, Brocklehurst P, Edwards D, Halliday H, Levene M, Thoresen M Whitelaw A, Group TS: The TOBY study. Whole body hypothermia for the treatment of perinatal asphyxial encephalopathy: a randomised controlled trial. BMC Pediatr. 2008:8:17.

23. Gluckman PD, Wyatt JS, Azzopardi D, Ballard R, Edwards AD, Ferriero DM, Polin RA, Robertson CM, Thoresen M, Whitelaw A, et al. Selective head cooling with mild systemic hypothermia after neonatal encephalopathy: multicentre randomised trial. Lancet. 2005;365(9460):663-70.

24. Shankaran S, Laptook AR, Ehrenkranz RA, Tyson JE, McDonald SA, Donovan EF, Fanaroff AA, Poole WK, Wright LL, Higgins RD, et al. Whole-body hypothermia for neonates with hypoxic-ischemic encephalopathy. N Engl J Med. 2005;353(15):1574-84.

25. Jacobs SE, Berg M, Hunt R, Tarnow-Mordi WO, Inder TE, Davis PG. Cooling for newborns with hypoxic ischaemic encephalopathy. Cochrane Database Syst Rev. 2013;1:CD003311.

26. Shankaran S, Pappas A, McDonald SA, Vohr BR, Hintz SR, Yolton K, Gustafson KE, Leach TM, Green C, Bara R, et al. Childhood outcomes after hypothermia for neonatal encephalopathy. N Engl J Med. 2012;366(22):2085-92.

27. Saliba E, Debillon T. Hypothermia for hypoxic-ischemic encephalopathy in fullterm newborns. Arch Pediatr. 2010;17(Suppl 3):S67-77.

28. Chevallier M, Ego A, Cans C, Debillon T. Adherence to hypothermia guidelines: a French multicenter study of fullterm neonates. PLoS One. 2013;8:e83742.

29. Amiel-Tison C. Update of the Amiel-Tison neurologic assessment for the term neonate or at 40 weeks corrected age. Pediatr Neurol. 2002;27(3):196-212.

30. Thompson CM, Puterman AS, Linley LL, Hann FM, van der Elst CW, Molteno CD, Malan AF. The value of a scoring system for hypoxic ischaemic encephalopathy in predicting neurodevelopmental outcome. Acta Paediatr. 1997;86(7):757-61.

31. Murray DM, Bala P, O'Connor CM, Ryan CA, Connolly S, Boylan GB. The predictive value of early neurological examination in neonatal hypoxic-ischaemic encephalopathy and neurodevelopmental outcome at 24 months. Dev Med Child Neurol. 2010;52(2):e55-9.

32. Monod N, Pajot N, Guidasci S. The neonatal EEG: statistical studies and prognostic value in full-term and pre-term babies. Electroencephalogr Clin Neurophysiol. 1972;32(5):529-44.

33. d'Allest AM, Andre M, Radvanyi-Bouvet MF. Contribution of electroencephalography to the diagnosis and prognosis of perinatal asphyxia in full-term neonates. Arch Pediatr. 1996;3(Suppl 1):254s-6s.

34. van Laerhoven $H$, de Haan TR, Offringa M, Post $B$, van der Lee JH. Prognostic tests in term neonates with hypoxic-ischemic encephalopathy: a systematic review. Pediatrics. 2013;131(1):88-98.

35. Mietzsch U, Parikh NA, Williams AL, Shankaran S, Lasky RE. Effects of hypoxic-ischemic encephalopathy and whole-body hypothermia on neonatal auditory function: a pilot study. Am J Perinatol. 2008;25(7):435-41.

36. Thoresen M, Hellstrom-Westas L, Liu X, de Vries LS. Effect of hypothermia on amplitude-integrated electroencephalogram in infants with asphyxia. Pediatrics. 2010;126(1):e131-9.

37. Barkovich AJ, Westmark K, Partridge C, Sola A, Ferriero DM. Perinatal asphyxia: MR findings in the first 10 days. AJNR Am J Neuroradiol. 1995;16(3):427-38.

38. Kuenzle C, Baenziger O, Martin E, Thun-Hohenstein L, Steinlin M, Good M, Fanconi S, Boltshauser E, Largo RH. Prognostic value of early MR imaging in term infants with severe perinatal asphyxia. Neuropediatrics. 1994;25(4):191-200.

39. McArdle CB, Richardson CJ, Hayden CK, Nicholas DA, Amparo EG. Abnormalities of the neonatal brain: MR imaging. Part II. Hypoxic-ischemic brain injury. Radiology. 1987;163(2):395-403.

40. Vermeulen RJ, Fetter WP, Hendrikx L, Van Schie PE, van der Knaap MS, Barkhof F. Diffusion-weighted MRI in severe neonatal hypoxic ischaemia: the white cerebrum. Neuropediatrics. 2003;34(2):72-6.

41. Wolf RL, Zimmerman RA, Clancy R, Haselgrove JH. Quantitative apparent diffusion coefficient measurements in term neonates for early detection of hypoxic-ischemic brain injury: initial experience. Radiology. 2001;218(3):825-33.

42. Chiesa C, Pellegrini G, Panero A, De Luca T, Assumma M, Signore F, Pacifico L. Umbilical cord interleukin-6 levels are elevated in term neonates with perinatal asphyxia. Eur J Clin Investig. 2003;33(4):352-8.
43. Walsh BH, Boylan GB, Livingstone V, Kenny LC, Dempsey EM, Murray DM. Cord blood proteins and multichannel-electroencephalography in hypoxic-ischemic encephalopathy. Pediatr Crit Care Med. 2013;14(6):621-30.

44. Shastri AT, Samarasekara S, Muniraman H, Clarke P. Cardiac troponin I concentrations in neonates with hypoxic-ischaemic encephalopathy. Acta Paediatr. 2012;101(1):26-9.

45. Simovic AM, Igrutinovic Z, Obradovic S, Ristic D, Vuletic B, Radanovic M. The significance of second generation cardiac troponin I in early screening of hypoxic-ischemic encephalopathy after perinatal asphyxia. Srp Arh Celok Lek. 2012;140(9-10):600-5.

46. Solberg R, Enot D, Deigner HP, Koal T, Scholl-Burgi S, Saugstad OD, Keller M. Metabolomic analyses of plasma reveals new insights into asphyxia and resuscitation in pigs. PLoS One. 2010;5(3):e9606.

47. Kumral A, Okyay E, Guclu S, Gencpinar P, Islekel GH, Oguz SS, Kant M, Demirel G, Duman N, Ozkan H. Cord blood ischemia-modified albumin: is it associated with abnormal Doppler findings in complicated pregnancies and predictive of perinatal asphyxia? J Obstet Gynaecol Res. 2013;39(3):663-71.

48. Bednarek N, Svedin P, Garnotel R, Favrais G, Loron G, Schwendiman L, Hagberg H, Morville P, Mallard C, Gressens P. Increased MMP-9 and TIMP-1 in mouse neonatal brain and plasma and in human neonatal plasma after hypoxia-ischemia: a potential marker of neonatal encephalopathy. Pediatr Res. 2012;71(1):63-70.

49. Hayakawa M, Ito Y, Saito S, Mitsuda N, Hosono S, Yoda H, Cho K, Otsuki K, Ibara S, Terui K, et al. Incidence and prediction of outcome in hypoxicischemic encephalopathy in Japan. Pediatr Int. 2014;56(2):215-21.

50. Simbruner G, Mittal RA, Rohlmann F, Muche R. Systemic hypothermia after neonatal encephalopathy: outcomes of neo.nEURO.Network RCT. Pediatrics. 2010;126(4):e771-8.

Ready to submit your research? Choose BMC and benefit from:

- fast, convenient online submission

- thorough peer review by experienced researchers in your field

- rapid publication on acceptance

- support for research data, including large and complex data types

- gold Open Access which fosters wider collaboration and increased citations

- maximum visibility for your research: over $100 \mathrm{M}$ website views per year

At BMC, research is always in progress.

Learn more biomedcentral.com/submissions 